\title{
Combined fracture and mortality risk evaluation for stratifying treatment in hip fracture patients: A feasibility study
}

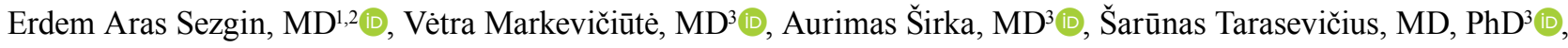 \\ Deepak Bushan Raina, $\mathrm{PhD}^{4}\left(\mathbb{D}\right.$, Hanna Isaksson, $\mathrm{PhD}^{4,5}$, , Magnus Tägil, $\mathrm{MD}, \mathrm{PhD}^{4}\left(\mathbb{D}\right.$, Lars Lidgren, $\mathrm{MD}, \mathrm{PhD}^{4}(\mathbb{D}$ \\ 'Department of Orthopedics and Traumatology, Medical Faculty of Gazi University, Ankara, Turkey \\ ${ }^{2}$ Department of Orthopaedics and Traumatology, Aksaray University Training and Research Hospital, Aksaray, Turkey \\ ${ }^{3}$ Department of Orthopaedics and Traumatology, Lithuanian University of Health Sciences, Kaunas, Lithuania \\ ${ }^{4}$ Department of Orthopaedics, Clinical Sciences Lund, Lund University, Lund, Sweden \\ ${ }^{5}$ Department of Biomedical Engineering, Lund University, Lund, Sweden
}

Osteoporosis associated fragility fractures in the elderly are a societal and financial burden in the western world and this burden has also started to affect developing nations with the increasing longevity. With the aging of the world's population, the age quake, hip fractures are expected to reach 2.6 million by the year 2025, and between 4.5 to 6.3 million by the year $2050 .{ }^{[1]}$ The mortality rate after sustaining a hip fracture is up to $10 \%$ at 30 days, and $35 \%$ at one year after the fracture ${ }^{[2]}$ It is further known that almost half of the survivors are unable to reach their previous functional levels, partly related to the surgical treatment and fixation failure. ${ }^{[3]}$

Augmentation of the fractured bone by injection of polymethyl methacrylate (PMMA) or synthetic bone into the femoral neck and trochanter could be of interest to improve the initial stability, particularly in patients with low bone quality, and therefore theoretically reduce the risk of fixation failure. ${ }^{[4,5]}$ Several techniques for augmentation described in

Received: January 13, 2020

Accepted: February 18, 2020

Published online: April 11, 2020

Correspondence: Erdem Aras Sezgin, MD. Aksaray Üniversitesi Eğitim ve Araştırma Hastanesi Ortopedi ve Travmatoloji Kliniği, 68200 Aksaray, Türkiye.

E-mail: sezginmd@hotmail.com

Doi: $10.5606 /$ ehc. 2020.73458

Citation: Sezgin EA, Markevičiūte V, Širka A, Tarasevičius S, Raina DB, Isaksson $\mathrm{H}$, et al. Combined fracture and mortality risk evaluation for stratifying treatment in hip fracture patients: A feasibility study. Jt Dis Relat Surg 2020;31(2):163-168.

\section{ABSTRACT}

Objectives: This study aims to test the feasibility of the Fracture and Mortality Risk Evaluation (FAME) Index.

Patients and methods: Two academic centers in Lithuania and Turkey participated in this retrospective study conducted between November 2018 and July 2019. A total of 100 consecutive patients (22 males, 78 females; mean age 78.9 years; range, 45 to 100 years) with low energy proximal femur fractures admitted for surgery were included in the study. Fracture Risk Assessment tool (FRAX) and the Sernbo scores were calculated and patients were classified into one of the nine subcategories of the FAME Index.

Results: Demographics and FAME Index classifications were similar between centers. Patients with high risk of fracture and low risk of mortality accounted for $18 \%$ of all patients, which is the FAME Index subcategory to theoretically benefit from cancellous bone augmentation during internal fixation of a fragility hip fracture the most.

Conclusion: The FAME Index was successfully applied in clinical emergency setting utilizing a simple form, and demonstrated promising potential in stratification of hip fractures most suitable for screw and device augmentation. Larger studies with at least one-year of follow-up are warranted to verify the validity of FAME Index.

Keywords: Hip fracture, index, osteoporosis, risk factors, stratification.

the literature are yet to prove their clinical efficiency. Furthermore, procedures to identify those patients that would benefit most from the augmentation need to be established.

The classical way of stratification for augmentation is according to fracture risk. Many tools have been used for identifying fracture risk and one of the most commonly used, the Fracture Risk Assessment 
tool (FRAX), was introduced in 2008. ${ }^{[6]}$ Fracture Risk Assessment tool provides the clinician with a 10-year probability of a fragility fracture, using basic clinical factors, with or without the use of bone mineral density (BMD) measurement. Recently, age dependent intervention thresholds based on FRAX risk scores have emerged as an effective method to categorize patients into high, intermediate and low risk groups. ${ }^{[6]}$

Besides future fracture risk, mortality risk could be a way to stratify treatment. There are several scoring systems to predict mortality risk after hip fractures. ${ }^{[7,8]}$ Most of these rely on detailed patient history, comorbidities and complex calculations which may require highly trained staff and may not be practical in the emergency setting. The Sernbo score, developed initially as a tool to aid deciding in between total hip arthroplasty (THA) and hemiarthroplasty in hip fracture patients, consists of four basic questions and has recently been shown to successfully estimate the postoperative one-month and one-year mortality rates after hip fractures in the elderly. ${ }^{[9]}$ In 2017, Mellner et al. ${ }^{[9]}$ defined three mortality risk groups using the Sernbo score; high, intermediate and low.

We hypothesized that FRAX tool and the Sernbo score can be combined to stratify patients with high risk of fracture and low risk of death, who would benefit most from augmentation procedures, before the operation. The aim of this study was therefore

\begin{tabular}{|c|c|c|c|c|c|}
\hline \multicolumn{6}{|c|}{ Fracture and Mortality Evaluation (FAME) Index } \\
\hline \multicolumn{6}{|l|}{ Patient ID: } \\
\hline \multicolumn{6}{|l|}{$\mathbf{A g e}^{(*)}\left[\geq 80\left({ }^{*} 2\right),<80\left({ }^{*} 5\right)\right]:$} \\
\hline \multicolumn{6}{|l|}{ Gender: } \\
\hline \multicolumn{6}{|l|}{ Weight (kg): } \\
\hline \multicolumn{6}{|l|}{ Height (cm): } \\
\hline \multicolumn{2}{|l|}{ Living ${ }^{(*)}$ : } & \multicolumn{2}{|c|}{ Own home ${ }^{(* 5)}$} & \multicolumn{2}{|c|}{ Sheltered home or frequent home assistance ${ }^{(* 2)}$} \\
\hline \multicolumn{2}{|l|}{ Walking aids ${ }^{(*)}$ : } & \multicolumn{2}{|c|}{ None, or one stick ${ }^{(* 5)}$} & \multicolumn{2}{|c|}{ Two sticks or walking frame ${ }^{(* 2)}$} \\
\hline \multicolumn{2}{|l|}{ Mental status( ${ }^{*}$ : } & \multicolumn{2}{|c|}{ Alert ${ }^{* 5}$} & \multicolumn{2}{|c|}{ Slight confusion ${ }^{(2)}$} \\
\hline \multicolumn{2}{|c|}{ Previous fracture Adult, $($ age +16$)$ low energy } & \multicolumn{2}{|c|}{ No } & \multicolumn{2}{|r|}{ Yes } \\
\hline \multicolumn{2}{|c|}{ Parent had hip fracture } & \multicolumn{2}{|c|}{ No } & & Yes \\
\hline \multicolumn{2}{|l|}{ Current smoking } & \multicolumn{2}{|c|}{ No } & & Yes \\
\hline \multicolumn{2}{|c|}{$\begin{array}{l}\text { Glucocorticoids (Current or previous at least } \\
3 \text { months of usage) }\end{array}$} & \multicolumn{2}{|c|}{ No } & & Yes \\
\hline \multicolumn{2}{|c|}{ Rheumatoid arthritis (Diagnosed) } & \multicolumn{2}{|c|}{ No } & & Yes \\
\hline \multicolumn{2}{|c|}{ 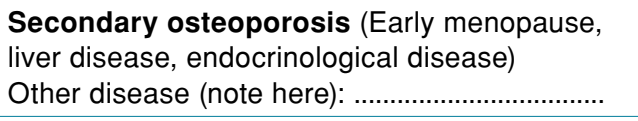 } & \multicolumn{2}{|c|}{ No } & & Yes \\
\hline \multicolumn{2}{|c|}{ Alcohol (3 or more units per day) } & \multicolumn{2}{|c|}{ No } & & Yes \\
\hline \multicolumn{2}{|c|}{ 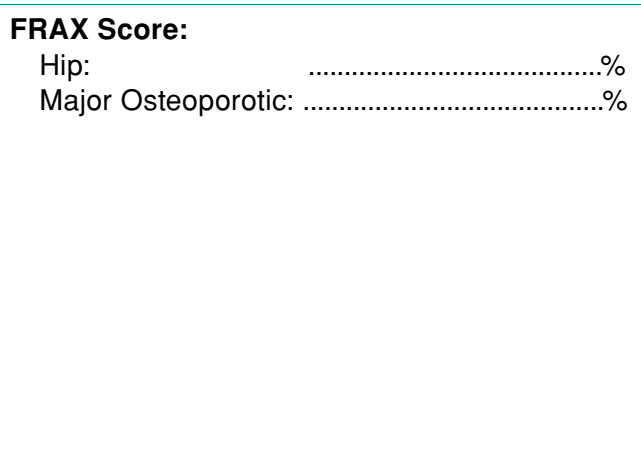 } & \multicolumn{4}{|c|}{ 10-year probability of major osteoporotic fracture (\%) } \\
\hline$\left(^{\star}\right)$ Sernbo Score: & Low Risk (20 an & & Intermedi & Risk (14) & High Risk (11 and 8) \\
\hline
\end{tabular}




\begin{tabular}{|c|c|c|c|c|c|c|c|c|}
\hline \multicolumn{9}{|c|}{$\begin{array}{l}\text { TABLE I } \\
\text { atients according to FAME Index in each center }\end{array}$} \\
\hline & \multicolumn{2}{|c|}{ Sernbo low } & \multicolumn{2}{|c|}{ Sernbo intermediate } & \multicolumn{2}{|c|}{ Sernbo high } & \multicolumn{2}{|c|}{ Total } \\
\hline & TUR & LIT & TUR & LIT & TUR & LIT & TUR & LIT \\
\hline FRAX low & 13 & 11 & 3 & 2 & 1 & 1 & 17 & 14 \\
\hline FRAX intermediate & 7 & 17 & 1 & 1 & 2 & 3 & 10 & 21 \\
\hline FRAX high & 9 & 9 & 9 & 1 & 5 & 5 & 23 & 15 \\
\hline Total & 29 & 37 & 13 & 4 & 8 & 9 & 50 & 50 \\
\hline
\end{tabular}

to demonstrate the feasibility of the combined index used in a clinical emergency setting and list the distribution of patients in nine sub-categories. The patients were stratified by a combination of each three risk categories (high, intermediate, low) from the FRAX and Sernbo score, which is named as Fracture And Mortality Risk Evaluation (FAME) Index.

\section{PATIENTS AND METHODS}

Lithuanian University of Health Sciences, Department of Orthopaedics and Traumatology in Kaunas, Lithuania and Gazi University Faculty of Medicine Hospital, Department of Orthopaedics and Traumatology in Ankara, Turkey participated in this preliminary retrospective study. Between November 2018 and July 2019, 100 consecutive patients (22 males, 78 females; mean age 78.9 years; range, 45 to 100 years), 50 from each center, with low energy fractures of the cervical or trochanteric region of the femur were admitted for surgery and included in the study. A written informed consent was obtained from each patient or their relatives. The study was conducted in accordance with the principles of the Declaration of Helsinki.

A combination of questions necessary to (i) calculate the possibility of major osteoporotic fracture using FRAX without BMD and (ii) classify the mortality risk using the Sernbo score were used to create a form (Figure 1). The forms were filled by orthopedic residents, medical interns or trained nurses at admission. The forms were collected and entered into a digital database. The FRAX risk score without BMD was calculated with data corrected for each country and the Sernbo scores according to original description. ${ }^{[9]}$ The treatment thresholds for FRAX without BMD in the United Kingdom were used to classify patients into high, medium and low fracture risk (Figure 1). ${ }^{[6]}$ Fracture Risk Assessment tool with BMD was not used to ensure simple and rapid application in the acute setting as well as to be able to apply aforementioned treatment thresholds for risk stratification. High risk was considered as an indicator of lowest bone quality. In addition, the patients were classified into high, medium and low mortality risk, using the mortality risk classification according to Sernbo score as modified by Mellner et al. ${ }^{[9]}$ (Figure 1). A FAME Index was created by classifying the patients into nine subcategories.

\section{Statistical analysis}

Statistical analysis was performed using the IBM SPSS version 22.0 software (IBM Corp., Armonk, NY. USA). Normality was assessed using the Shapiro-Wilk

\begin{tabular}{|c|c|c|c|c|c|c|c|}
\hline \multicolumn{8}{|c|}{$\begin{array}{l}\text { TABLE II } \\
\text { Comparison of patient demographics between centers }\end{array}$} \\
\hline & \multicolumn{3}{|c|}{ Turkey } & \multicolumn{3}{|c|}{ Lithuania } & \multirow[b]{2}{*}{$p$} \\
\hline & $\mathrm{n}$ & Mean & $95 \% \mathrm{Cl}$ & $\mathrm{n}$ & Mean & $95 \% \mathrm{Cl}$ & \\
\hline Gender & & & & & & & 0.3 \\
\hline Male & 9 & & & 13 & & & \\
\hline Female & 41 & & & 37 & & & \\
\hline Mean age (year) & & 78 & $74.9-81.2$ & & 79.7 & $77.2-82.3$ & 0.4 \\
\hline Mean weight (kg) & & 65.3 & $61.5-69.2$ & & 67.2 & $62.7-71.7$ & 0.5 \\
\hline Mean height $(\mathrm{cm})$ & & 159.6 & $157.5-161.7$ & & 164.9 & $162.5-167.3$ & 0.001 \\
\hline
\end{tabular}




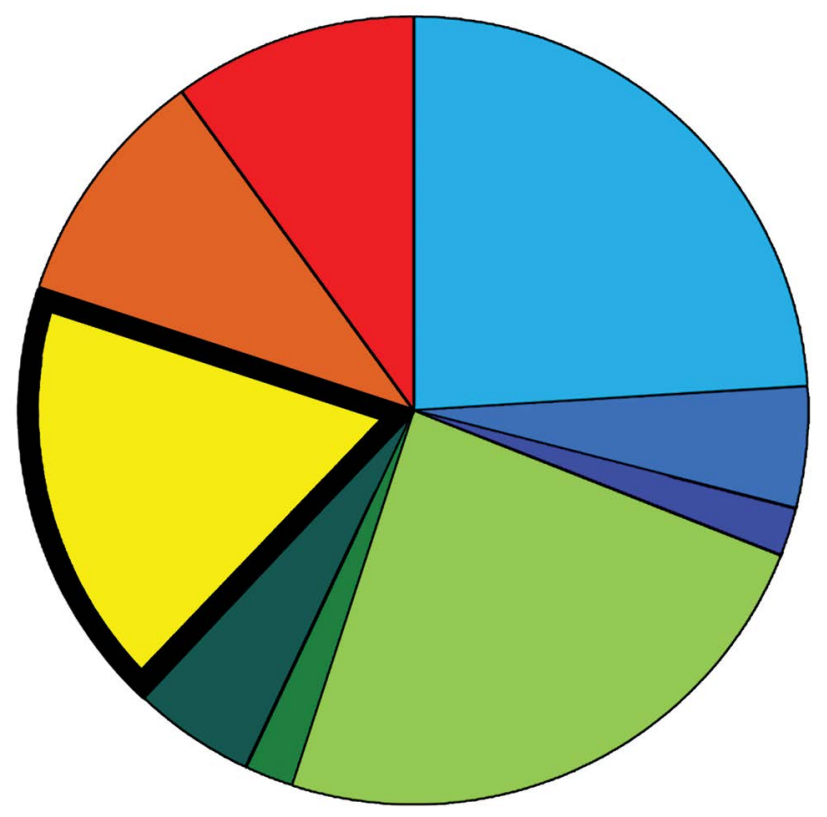

FIGURE 2. Pie-chart representation of combined FAME Index subgroups from both centers. Each color represents one of nine subgroups of the FAME Index as illustrated in Table 1. Yellow section with thick borders represents subgroup with high risk of fracture and low risk of mortality. FAME: Fracture and Mortality Risk Evaluation.

normality test. Differences between the two centers were tested. Categories of FAME Index including gender, age, height and weight were assessed using the chi-square test for categorical variables and independent-samples t-test or Mann-Whitney $U$ test for continuous variables. $P$ values of $<0.05$ were considered statistically significant.

\section{RESULTS}

Data were available for 50 patients from each center, and the distribution of patients in different FAME Index categories did not differ between the centers (Table I). There was no statistically significant difference between patients from the two centers for gender, age and weight; however, the Lithuanian cohort was taller $(\mathrm{p}=0.001)$ (Table II).

The subgroup with patients having high risk of fracture while having low risk of mortality accounted for $18 \%$ of all patients (Figure 2).

\section{DISCUSSION}

The direct and indirect costs in the first year following a hip fracture were estimated to be $\$ 43,669$ in the year 2014 by Williamson et al. ${ }^{[1]}$ Moreover, these calculations do not include the societal impact of caregiving by relatives. Altogether, this translates to more than a hundred billion Unites States dollars being spent globally each year; more than breast and gynecological cancers combined. ${ }^{[10]}$

Hip arthroplasty and internal fixation are the two most common treatment options for cervical and trochanteric femoral fractures ${ }^{[11,12]}$ Healthier patients with long life expectancy have better functional recovery and lower mortality when internal fixation is used. ${ }^{[13]}$ However, dynamic hip screws (DHS) and intramedullary nails and screws are associated with high failure rates, particularly in unstable trochanteric fractures. ${ }^{[14]}$ Osteosynthesis cutout, with penetration of the cervical screw through the femoral head, preceded by a neck-shaft varus tilting, is the most common reason of failure, reported in up to $10 \%$ in trochanteric fractures, and in about $5 \%$ of neck fractures. ${ }^{[15]}$ In addition, reoperations have been reported to be as high as $30 \%$, where treatment of dislocated femoral neck fracture with internal fixation fails and subsequently gets revised with THA. ${ }^{[15,16]}$ It is well established that salvage THA following hip fractures has significantly higher risk of complications compared to primary THA. ${ }^{[16]}$ The tip-apex distance has been defined as a strong predictor of screw cutout, while recent studies question its relevance. ${ }^{[17]}$ The bone quality, i.e. the degree of osteoporosis, on the other hand is associated with failures. ${ }^{[4]}$ Despite the increase in clinical awareness; adoption of secondary preventation using bisphosphantes is still low, partly due to low patient adherence. ${ }^{[18]}$ Besides, even if included in a dual-energy X-ray absorptiometry surveillance program, there is a delayed response to bisphosphonate treatment, which has been deemed critical, during the first one and half years. ${ }^{[19]}$ Augmentation increasing mechanical strength of cancellous bone in osteoporotic hip fractures may lower the burden of revision, which may outweigh the related additional cost. Before the operation, deciding in whom to augment is a challenge.

Hip fracture augmentation has been described by injection of PMMA or ceramics. ${ }^{[5,20]}$ Many different techniques and materials used in fragile bone were described in clinical and in vivo studies as well as in computer models. ${ }^{[4,5]}$ However, data available are scattered. PMMA is today the only approved augmentation material for cannulated and fenestrated screws in the spine and the use has not been widely spread and search for alternative methods continues. ${ }^{[5]}$ A pilot study by Širka et al. ${ }^{[20]}$ indicated that local delivery of a bisphosphonate, zoledronic acid (ZA), using the calcium sulphate/hydroxyapatite 
(CaS/HA) biomaterial enhanced bone formation in the femoral neck canal of severely osteoporotic rats. Moreover, recently, Raina et al. ${ }^{[2]}$ confirmed the findings also in a screw implant-integration model in rats. Whether these studies will show a similar potential in the clinical scenarios is a matter of speculation; however, they do provide novel methods for augmenting bone quality in osteoporosis as well as improving screw fixation. It is however important to mention that local delivery of ZA has a profound effect on cancellous bone regeneration in healthy as well as osteoporotic while the effect on cortical bone is minimal. ${ }^{[20]}$ A finite element modeling study by Kok et al., ${ }^{[22]}$ used computer simulations to predict the effect of CaS/HA augmentation in the form of injections into the human femoral heads/femoral neck canal and indicated enhanced mechanical properties by up to $25 \%$ which were dependent on volume and location of the injection. In a limited one-year followup study, the use of an injectable ceramic applied in the trochanteric fracture bone void has been shown to lead to adequate fracture healing with minimal DHS screw migration. ${ }^{[4]}$

Neither dual X-ray absorptiometry nor quantitative computed tomography (QCT) is an ideal assessment tool measuring bone quality after a hip fracture. On the other hand, volumetric BMD methods with voxel-based morphometry and spatial assessment from QCT images have been validated and applied in hip fracture studies, in a clinical setting with the non-fractured femoral head canal, the tentative screw canal and its surrounding as the region of interest. ${ }^{[23]}$ In today's clinical practice, regular X-ray of the fractured hip is standard. However, CT is evolving as a routine examination in emergency settings and is not significantly more time-consuming. In addition, QCT of the hip is not associated with critical extra radiation exposure, particularly in the old population. ${ }^{[2]}$ Standardized automated digital method using QCT may identify what type of fixation device or augmentation is best for specific hip fracture patients and may, in the future, be combined with the Sernbo to form the FAME index for stratification of hip fractures.

It is reasonable to argue that patients with high fracture and low mortality risks would benefit from an augmentation procedure far more than the ones with low fracture and high mortality risks. In this study, by combining the well-established FRAX and the Sernbo score to form a FAME Index, one fifth of the patients could be identified as a cohort, with high risk of subsequent fracture but low risk of mortality. This group could theoretically benefit from cancellous bone augmentation during internal fixation of a fragility hip fracture. By utilizing a simple form, the FAME Index was successfully applied in the acute setting before the operation, during history taking by well-informed medical staff in less than 10 minutes.

We recognize several limitations to the study. The number of patients enrolled were based on clinical decision. Additional recruitment could have given minor adjustments of the groups. We have used a FRAX classification excluding bone mineral density measurement. Moreover, we have not performed a follow-up of enrolled patients thus, definite long term outcome remains to be evaluated. However, it has been comprehensively reported in the literature that both FRAX and Sernbo scores can separately be utilized successfully to estimate fracture and mortality risk.

In conclusion, screw and device augmentation in hip fractures is still up to debate and data from randomized controlled trials (RCTs) are required to be able to verify its efficacy. Without stratification of patients, these RCTs may provide scattered data, which decreases the scientific value and increases the size and cost of the study; therefore jeopardizes the clinical adaptation. Using the FAME Index for stratification of hip fractures may provide a solid base for RCTs justifying the costs emanating from either governmental or industrial sources.

\section{Declaration of conflicting interests}

LL is a board member of Bone Support AB, Lund, Sweden and Ortho Cell, Australia. The authors declared no conflicts of interest with respect to the authorship and/or publication of this article.

\section{Funding}

The financial support to the researchers was granted by VINNOVA innovation agency in Sweden (grant 2017-00269), VR-The Swedish Research Council (grant 2015-06717) and the Foundation for Disabled people in Scania, Sweden. The funding bodies had no role in the design of the study, data collection, analysis, and interpretation of data or in writing the manuscript.

\section{REFERENCES}

1. Williamson S, Landeiro F, McConnell T, Fulford-Smith L, Javaid MK, Judge A, et al. Costs of fragility hip fractures globally: a systematic review and meta-regression analysis. Osteoporos Int 2017;28:2791-800.

2. Chia PH, Gualano L, Seevanayagam S, Weinberg L. Outcomes following fractured neck of femurin an Australian metropolitan teaching hospital. Bone Joint Res 2013;2:162-8.

3. Braithwaite RS, Col NF, Wong JB. Estimating hip fracture morbidity, mortality and costs. J Am Geriatr Soc 2003;51:364-70.

4. Stravinskas M, Tarasevicius S, Laukaitis S, Nilsson M, Raina DB, Lidgren L. A ceramic bone substitute containing 
gentamicin gives good outcome in trochanteric hip fractures treated with dynamic hip screw and in revision of total hip arthroplasty: a case series. BMC Musculoskelet Disord 2018;19:438.

5. Kammerlander C, Neuerburg C, Verlaan JJ, Schmoelz W, Miclau T, Larsson S. The use of augmentation techniques in osteoporotic fracture fixation. Injury 2016;47:S36-43.

6. Compston J, Cooper A, Cooper C, Gittoes N, Gregson C, Harvey $\mathrm{N}$, et al. UK clinical guideline for the prevention and treatment of osteoporosis. Arch Osteoporos 2017;12:43.

7. van Zeeland ML, Genovesi IP, Mulder JW, Strating PR, Glas AS, Engel AF. POSSUM predicts hospital mortality and long-term survival in patients with hip fractures. J Trauma 2011;70:E67-72.

8. Wiles MD, Moran CG, Sahota O, Moppett IK. Nottingham Hip Fracture Score as a predictor of one year mortality in patients undergoing surgical repair of fractured neck of femur. Br J Anaesth 2011;106:501-4.

9. Mellner C, Eisler T, Börsbo J, Brodén C, Morberg P, Mukka $\mathrm{S}$. The Sernbo score predicts 1-year mortality after displaced femoral neck fractures treated with a hip arthroplasty. Acta Orthop 2017;88:402-6.

10. Hernlund E, Svedbom A, Ivergård M, Compston J, Cooper C, Stenmark J, et al. Osteoporosis in the European Union: medical management, epidemiology and economic burden. A report prepared in collaboration with the International Osteoporosis Foundation (IOF) and the European Federation of Pharmaceutical Industry Associations (EFPIA). Arch Osteoporos 2013;8:136.

11. Kaplan K, Miyamoto R, Levine BR, Egol KA, Zuckerman JD. Surgical management of hip fractures: an evidence-based review of the literature. II: intertrochanteric fractures. J Am Acad Orthop Surg 2008;16:665-73.

12. Esen E, Dur H, Ataoğlu MB, Ayanoğlu T, Turanlı S. Evaluation of proximal femoral nail-antirotation and cemented, bipolar hemiarthroplasty with calcar replacement in treatment of intertrochanteric femoral fractures in terms of mortality and morbidity ratios. Eklem Hastalik Cerrahisi 2017;28:35-40.

13. Kumar P, Rajnish RK, Sharma S, Dhillon MS. Proximal femoral nailing is superior to hemiarthroplasty in $\mathrm{AO} /$ OTA A2 and A3 intertrochanteric femur fractures in the elderly: a systematic literature review and meta-analysis. Int Orthop 2020;44:623-33.
14. Li S, Chang SM, Niu WX, Ma H. Comparison of tip apex distance and cut-out complications between helical blades and lag screws in intertrochanteric fractures among the elderly: a meta-analysis. J Orthop Sci 2015;20:1062-9.

15. Jiang J, Yang CH, Lin Q, Yun XD, Xia YY. Does arthroplasty provide better outcomes than internal fixation at mid- and long-term followup? A meta-analysis. Clin Orthop Relat Res 2015;473:2672-9.

16. Mahmoud SS, Pearse EO, Smith TO, Hing CB. Outcomes of total hip arthroplasty, as a salvage procedure, following failed internal fixation of intracapsular fractures of the femoral neck: a systematic review and meta-analysis. Bone Joint J 2016;98-B:452-60.

17. Goffin JM, Pankaj P, Simpson AH. The importance of lag screw position for the stabilization of trochanteric fractures with a sliding hip screw: a subject-specific finite element study. J Orthop Res 2013;31:596-600.

18. Bozkurt HH, Atik OŞ, Tokgöz MA. Can distal radius or vertebra fractures due to low-energy trauma be a harbinger of a hip fracture? Eklem Hastalik Cerrahisi 2018;29:100-3.

19. Ferrari S, Reginster JY, Brandi ML, Kanis JA, Devogelaer JP, Kaufman JM, et al. Unmet needs and current and future approaches for osteoporotic patients at high risk of hip fracture. Arch Osteoporos 2016;11:37.

20. Širka A, Raina DB, Isaksson H, Tanner KE, Smailys A, Kumar A, et al. Calcium Sulphate/Hydroxyapatite Carrier for Bone Formation in the Femoral Neck of Osteoporotic Rats. Tissue Eng Part A 2018. [Epub ahead of print]

21. Raina DB, Larsson D, Sezgin EA, Isaksson H, Tägil M, Lidgren L. Biomodulation of an implant for enhanced boneimplant anchorage. Acta Biomater 2019;96:619-30.

22. Kok J, Širka A, Grassi L, Raina DB, Tarasevičius Š, Tägil $\mathrm{M}$, et al. Fracture strength of the proximal femur injected with a calcium sulfate/hydroxyapatite bone substitute. Clin Biomech (Bristol, Avon) 2019;63:172-8.

23. Zhang R, Wang L, Lin Y, Yang M, Guo Z, Xia W, et al. A novel method for estimating nail-tract bone density for intertrochanteric fractures. J Orthop Translat 2018;18:40-7.

24. Engelke K, Adams JE, Armbrecht G, Augat P, Bogado $\mathrm{CE}$, Bouxsein $\mathrm{ML}$, et al. Clinical use of quantitative computed tomography and peripheral quantitative computed tomography in the management of osteoporosis in adults: the 2007 ISCD Official Positions. J Clin Densitom 2008;11:123-62. 